\title{
EIF3F-related neurodevelopmental disorder: refining the phenotypic and expanding the molecular spectrum
}

Ulrike Hüffmeier ${ }^{1 *}$ (D), Cornelia Kraus ${ }^{1}$, Miriam S. Reuter ${ }^{1}$, Steffen Uebe ${ }^{1}$, Mary-Alice Abbott², Syed A. Ahmed ${ }^{3}$, Kristyn L. Rawson ${ }^{3}$, Eileen Barr ${ }^{4}$, Hong Li ${ }^{4}$, Ange-Line Bruel ${ }^{5,6}$, Laurence Faivre ${ }^{5,7}$, Frédéric Tran Mau-Them ${ }^{5,6}$, Christina Botti ${ }^{8}$, Susan Brooks ${ }^{8}$, Kaitlyn Burns ${ }^{9}$, D. Isum Ward ${ }^{9}$, Marina Dutra-Clarke ${ }^{10}$, Julian A. Martinez-Agosto ${ }^{10,11}$, Hane Lee ${ }^{11,12}$, Stanley F. Nelson ${ }^{10,11,12}$, UCLA California Center for Rare Disease $^{13}$, Pia Zacher ${ }^{14,15}$, Rami Abou Jamra ${ }^{14}$, Chiara Klöckner ${ }^{14}$, Julie McGaughran ${ }^{16,17}$, Jürgen Kohlhase ${ }^{18}$, Sarah Schuhmann', Ellen Moran ${ }^{19}$, John Pappas ${ }^{20}$, Annick Raas-Rothschild ${ }^{21,22}$, Maria J. Guillen Sacoto ${ }^{23}$, Lindsay B. Henderson ${ }^{23}$, Timothy Blake Palculict ${ }^{23}$, Sureni V. Mullegama ${ }^{23}$, Houda Zghal Elloumi ${ }^{23}$, Adi Reich ${ }^{23}$, Samantha A. Schrier Vergano ${ }^{24}$, Erica Wahl ${ }^{25}$, André Reis ${ }^{1}$ and Christiane Zweier ${ }^{1,26}$

\begin{abstract}
Background: An identical homozygous missense variant in EIF3F, identified through a large-scale genome-wide sequencing approach, was reported as causative in nine individuals with a neurodevelopmental disorder, characterized by variable intellectual disability, epilepsy, behavioral problems and sensorineural hearing-loss. To refine the phenotypic and molecular spectrum of EIF3F-related neurodevelopmental disorder, we examined independent patients.

Results: 21 patients were homozygous and one compound heterozygous for c.694T>G/p.(Phe232Val) in EIF3F. Haplotype analyses in 15 families suggested that c.694T>G/p.(Phe232Val) was a founder variant. All affected individuals had developmental delays including delayed speech development. About half of the affected individuals had behavioral problems, altered muscular tone, hearing loss, and short stature. Moreover, this study suggests that microcephaly, reduced sensitivity to pain, cleft lip/palate, gastrointestinal symptoms and ophthalmological symptoms are part of the phenotypic spectrum. Minor dysmorphic features were observed, although neither the individuals'facial nor general appearance were obviously distinctive. Symptoms in the compound heterozygous individual with an additional truncating variant were at the severe end of the spectrum in regard to motor milestones, speech delay, organic problems and pre- and postnatal growth of body and head, suggesting some genotype-phenotype correlation.
\end{abstract}

Conclusions: Our study refines the phenotypic and expands the molecular spectrum of EIF3F-related syndromic neurodevelopmental disorder.

Keywords: EIF3F gene, Neurodevelopmental disorder, Short stature, Deafness, Behavioral difficulties, Altered muscular tone

\footnotetext{
*Correspondence: ulrike.hueffmeier@uk-erlangen.de

${ }^{1}$ Institute of Human Genetics, Universitätsklinikum Erlangen, Friedrich-

Alexander-Universität Erlangen-Nürnberg (FAU), Schwabachanlage 10, 91054 Erlangen, Germany

Full list of author information is available at the end of the article
}

\section{Introduction}

Bi-allelic variants in the EIF3F gene have recently been published as the cause for a syndromic neurodevelopmental disorder (NDD) (OMIM \#618,295: intellectual developmental disorder, autosomal recessive 67).

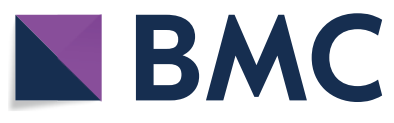

(c) The Author(s) 2021. Open Access This article is licensed under a Creative Commons Attribution 4.0 International License, which permits use, sharing, adaptation, distribution and reproduction in any medium or format, as long as you give appropriate credit to the original author(s) and the source, provide a link to the Creative Commons licence, and indicate if changes were made. The images or other third party material in this article are included in the article's Creative Commons licence, unless indicated otherwise in a credit line to the material. If material is not included in the article's Creative Commons licence and your intended use is not permitted by statutory regulation or exceeds the permitted use, you will need to obtain permission directly from the copyright holder. To view a copy of this licence, visit http://creativecommons.org/licenses/by/4.0/. The Creative Commons Public Domain Dedication waiver (http://creativeco mmons.org/publicdomain/zero/1.0/) applies to the data made available in this article, unless otherwise stated in a credit line to the data. 
Variants were identified by a large exome-wide recessive burden analysis of $>4500$ families with no previous molecular diagnosis [9]. All nine affected individuals from seven families carried the same homozygous EIF3F missense variant c.694T >G/p.(Phe232Val). Beside variable intellectual disability (ID) in all individuals, epilepsy occurred in six, and behavioral problems or sensorineural hearing loss in three individuals, respectively [9]. Rarer malformations described in single individuals were bilateral cleft lip and palate, congenital lobar emphysema, anal stenosis and undescended testis. Neurological rarer symptoms included a high pain threshold, drop attacks, muscular hypoplasia; upon brain imaging, an arachnoid cyst in the right cerebellar pontine angle, prominent perivascular spaces and mild tonsillar ectopia were observed in single patients.

EIF3F encodes an essential subunit of the largest eukaryotic translation initiation factor eIF3 which binds to a highly specific group of mRNAs involved in cell proliferation and growth, including cell cycle control, differentiation and apoptosis $[8,10]$. In vitro studies of induced pluripotent stem cells (iPSC), gene-edited to be homozygous for the c.694T>G/ p.(Phe232Val) variant, demonstrated lower EIF3F protein levels and reduced proliferation rates [9]. Furthermore, both heterozygous and homozygous variants reduced translation rates in iPSC cells [9], suggesting a loss-of-function mechanism.

In the current study, we assembled a group of 21 previously unreported individuals with homozygosity or compound heterozygosity for the variant c.694T>G/ p.(Phe232Val). We refine the EIF3F-related phenotypic spectrum in this group and describe an additional, so far unreported disease-causing variant. Thus, we confirm EIF3F-deficiency as a relatively prevalent cause for autosomal-recessive NDD.

\section{Methods}

\section{Editorial policies and ethical considerations}

Individual genetic testing was performed either in diagnostic or research settings. The study was approved by the ethical committee of the Friedrich-Alexander-Universität Erlangen-Nürnberg, and by local institutional review boards of the contributing institutions where applicable.

\section{Affected individuals}

The study group was gathered through GeneMatcher [14], and internal collaborations, such as the corresponding authors of [9]. Parents or the legal guardians gave written informed consent before enrollment. Investigations were conducted according to Declaration of Helsinki principles.

\section{Methods}

A questionnaire filled out by the patient's clinical team was used to collect detailed clinical characteristics of affected individuals with bi-allelic EIF3F variants. To normalize body measurements (height, weight and head circumference) to the corresponding age, the publicly available data-source "https://www.pedz.de/" based on birth data by Voigt et al. [17] and studies reported by Kromeyer-Hauschild et al. [7] for older age groups were used.

EIF3F variants were identified by sequencing of autism/ intellectual disability gene panels, whole exome sequencing (WES) or whole genome sequencing, performed as a clinical test or within a research project as described previously [4, 12, 13], or by Sanger sequencing for co-segregation testing in core family members, as presented in Additional file 1: Table S1 and Additional file 2: Fig. S1.

We used genotypes of 136 frequent SNPs (MAF > 5\%) generated from internal WES data (1818 independent samples, affected individual and parents of P13 and one affected individual of P14) covering EIF3F and its flanking regions (chr11: 7,614,107-8,413,933 (hg19)). We defined haplotype blocks using the definition of the model "solid spine of linkage disequilibrium (LD)" in Haploview [2] and determined haplotypes at an individual basis using PHASE vs.2.1.1 [15] as described previously [5]. Within the LD block of EIF3F, five of seven common SNPs (rs79714374, rs12421289, rs12278319, rs7941782, rs4758267, rs12420464, rs56392532) were identified to be tagging SNPs for six different haplotypes with frequencies between 3.5 and $53.4 \%$. The set of seven SNP was used to assess the haplotypes in other affected individuals with the homozygous EIF3F missense variant and if available, their parents. Some redundantly tagged SNPs (rs79714374 and rs56392532) had a coverage of $<10 \times$ in affected individuals of $\mathrm{P} 2$, P3, P6, P10, P12, P17 (Table 1), but due to very high linkage disequilibrium in 1818 WES, their genotypes could be tagged by rs12420464 and rs12421289, respectively. Genotypes of rs12278319 in mother of P10 and of rs79714374 and rs12420464 in the affected individual of P17 could be inferred in single individuals of P10, P17 due to available genotypes in other core family members, and the ones of two SNPs in P4 (rs79714374, rs12420464) could be deduced to one of the haplotypes identified in 1818 WES data. Due to insufficient coverage of two SNPs $(<15 \mathrm{x})$ in the affected individual of P16, the DNA was sequenced by Sanger for rs12278319 and rs12420464. 


\section{Results}

We identified the same homozygous missense variant c.694T > G/ p.(Phe232Val) in EIF3F (NM_003754) in 21 individuals from 16 families (Fig. 1). All tested parents were heterozygous carriers of the variant (parents of pedigree 16 (P16) were not available for testing). Parental consanguinity was reported in one of 16 families. An additional affected individual (P3) was compound heterozygous for the maternally inherited missense variant c.694T > G/ p.(Phe232Val) and a paternally inherited variant c.861dup/ p.(Gln288AlafsTer14). The latter variant was absent in the Genome Aggregation Database (gnomAD) [6], and was predicted to result in a frameshift and subsequently either in mRNA decay or a truncated protein (length reduced by $20 \%$, exon 6 of 8 ) with altered structure.

The female individual of family P2 had two molecular diagnoses. In addition to the homozygous EIF3F variant, she had a de novo frameshift variant in $M E C P 2$, implicated in Rett syndrome (OMIM \#312750). As symptoms in EIF3F-related NDD considerably overlap with those in Rett syndrome, we did not include this individual in the summary of clinical aspects (Table 2), but presented details in Additional file 1: Table S1.

Among the reported individuals were 15 females (14 total when excluding the individual with Rett syndrome) and 7 males. Overall, history of pregnancies and deliveries were largely uneventful, although oligohydramnios was noted in one pregnancy (P9), and perinatal asphyxia suspected in another case (P14). The average age at the time of the last physical examination was $12.1 \pm 9.6$ years (mean \pm standard deviation), with a median of 8.5 years; four individuals had an age of $>18$ years.

All affected individuals had developmental delays. Considering motor milestones, $33 \%$ of ascertained individuals $(4 / 12)$ exhibited delays in unassisted sitting (>10 months) and $70 \%$ of individuals $(14 / 20)$ in independent walking ( $\geq 18$ months, Additional file 1: Table S1). The single individual with compound heterozygous EIF3F variants (P3) did not walk independently at the age of 5 years, but crawled. $24 \%$ of individuals (5/21) had not developed speech at the last examination including the compound heterozygous individual, while speech abilities varied widely between few words and simplified, but usable language in the remaining individuals.

Hearing loss was reported in $57 \%$ of affected individuals $(12 / 21)$. More than half of the probands $(12 / 21$; $57 \%$ ) were observed to have behavioral problems such as obsessive compulsory disorder, social problems, anxiety, autism, hyperactivity, attention deficit, aggressivity or pica. Muscular hypo- or hypertonia was also common and diagnosed in $48 \%$ of affected individuals (10/21). Notably, different ophthalmological findings were observed in up to $38 \%$ of affected individuals $(8 / 21)$ and included hyper-/myopia (38\%), strabismus (14\%), nystagmus (5\%) and coloboma (5\%). Brain imaging revealed nonspecific findings in five of 13 examined affected individuals (38\%). Five of 21 individuals (24\%) had sleeping problems. Epilepsy was diagnosed in $15 \%$ of individuals (3/20).

Regression of cognitive abilities was observed in three of 21 individuals at an age of 2.5 years (P11.1), 21 years (P4.1) and in adulthood (P14). Two of these lost their speech abilities, while the third developed mood swings and demanded more attention. P14 had a combination of meningioma and psychosis, and an additional individual (P16) was operated on a meningioma.

Two individuals were noted to have reduced pain sensitivity. In one proband, muscle atrophy was noted, while in two of the ten individuals with altered muscular tone, a combination of truncal hypotonia and hypertonic extremities was diagnosed.

Short stature was observed in $40 \%$ of affected individuals at the last physical examination (Table 2, Additional file 1: Table S1). Interestingly, four of the seven individuals with short stature at the last examination (with available data of body length at birth and at the last examination), had normal body length at birth. Microcephaly was common at the last physical examination $(6 / 19 ; 32 \%)$, and microcephaly $(4 / 10 ; 40 \%)$ or normocephaly $(6 / 10 ; 60 \%)$ remained consistent between birth and the last measurement. Notably, the compound heterozygous individual of P3 was both short for age and microcephalic.

Five of the individuals (24\%) had gastrointestinal problems which included gastro-esophageal reflux disease, difficulties to swallow, alternating constipation and diarrhea and neonatal feeding problems. Cleft lip and palate (P15), tetralogy of Fallot (P3) or combination (P5) of a groove of lip (considered a minor variant of cleft lip, Fig. 2c, d) and a nasal fistula (Fig. 2c) were observed in a single individual each. The compound heterozygous individual had gastrointestinal problems and a congenital heart defect.

More prevalent dysmorphic findings included a tubular and/ or narrow nose, a pointed nasal tip and anteverted nares. We also observed posteriorly rotated ears, short and/ or encased (=embedded by abundant skin) finger and toe nails (Fig. 2, Table 2). Also, palpebral fissures were fairly even in all affected individuals (Fig. 2). A unilateral single palmar crease was noted in four individuals. Dysmorphic features were generally subtle and non-specific and were not considered a recognizable facial gestalt.

Two individuals had initially received targeted diagnostics for short stature or failure to thrive including a 
Table 1 Haplotypes at EIF3F in 15 families

\begin{tabular}{|c|c|c|c|}
\hline \multirow[t]{2}{*}{ Pedigree } & \multicolumn{3}{|c|}{ Combination of haplotypes in... } \\
\hline & ...Affected individual & $\begin{array}{l}\text {...Mother (frequency of 2nd } \\
\text { haplotype) }\end{array}$ & $\begin{array}{l}\text {... Father (frequency of 2nd } \\
\text { haplotype) }\end{array}$ \\
\hline P1 & CCACCGC/CCACCGC & CCACCGC/CCACTGC (0.534) & CCACCGC/CTGCTGT (0.124) \\
\hline P2 & {$[\mathrm{C}] \mathrm{CACCGC/[C]CACCGC}$} & {$[\mathrm{C}] \mathrm{CACCGC/[C]CACTGC}(0.534)$} & {$[C] C A C C G C /[C] C G A C G C(0.158)$} \\
\hline P3 & {$[\mathrm{C}] \mathrm{CACCGC} /[\mathrm{C}] \mathrm{CGACGC}^{\S}$} & {$[C] C A C C G[C] /[C] C A C T G[C](0.534)$} & {$[\mathrm{C}] \mathrm{CGACG}[\mathrm{Cl}]^{\S} /[\mathrm{C}] \mathrm{CACTG}[\mathrm{C}](0.534)$} \\
\hline P4 & {$[c] C A C C[g] C /[c] C A C C[g] C$} & {$[\mathrm{c}] \mathrm{CACC}[\mathrm{g}] \mathrm{C} /[\mathrm{c}] \mathrm{CGCC}[\mathrm{c}] \mathrm{C}(0.095)$} & {$[\mathrm{c}] \mathrm{CACC}[\mathrm{g}] \mathrm{C} /[\mathrm{c}] \mathrm{CACT}[\mathrm{g}] \mathrm{C}(0.534)$} \\
\hline P6 & CCACCGC/CCACCGC & [C]CACCGC/[C]CGCCGC (0.095) & {$[\mathrm{C}] \mathrm{CACCG}[\mathrm{C}] /[\mathrm{C}] \mathrm{CGACG}[\mathrm{C}](0.158)$} \\
\hline P7 & CCACCGC/CCACCGC & CCACCGC/CTGCTGT (0.124) & CCACCGC/CCACCGC (0.035) \\
\hline P9 & CCACCGC/CCACCGC & CCACCGC/CCACTGC (0.534) & CCACCGC/CCGCCGC (0.095) \\
\hline P10 & {$[\mathrm{C}] \mathrm{CACCGC} /[\mathrm{C}] \mathrm{CACCGC}$} & {$[\mathrm{C}] \mathrm{CCCG}[\mathrm{C}] /[\mathrm{C}] \mathrm{C}[\mathrm{x}] \mathrm{CTG}[\mathrm{C}]$ (n.a.) } & {$[\mathrm{C}] \mathrm{CACCG}[\mathrm{C}] /[\mathrm{C}] \mathrm{CACTG}[\mathrm{C}](0.534)$} \\
\hline P11 & CCACCGC/CCACCGC & CCACCGC/CCACTGC (0.534) & CCACC[G]C/CCACT[G]C (0.534) \\
\hline P12 & {$[\mathrm{C}] \mathrm{CACCGC} /[\mathrm{C}] \mathrm{CACCGC}$} & CCACCGC/TTGCTTT (0.047) & [C]CACCGC/[C]CACTGC (0.534) \\
\hline P13 & CCACCGC/CCACCGC & CCACCGC/CCGCCGC (0.095) & CCACCGC/CCACTGC (0.534) \\
\hline P14 & CCACCGC/CCACCGC & No WES & NoWES \\
\hline P15 & CCACCGC/CCACCGC & NoWES & NOWES \\
\hline P16 & CCACCGC/CCACCGC & NOWES & NOWES \\
\hline P17 & $\{C\} C A C C\{G\} C /\{C\} C A C C\{G\} C$ & CCACC[G]C/CTGCT[G]T (0.124) & CCACCGC/CCACTGC (0.534) \\
\hline
\end{tabular}

For haplotype analyses, seven intragenic SNPs were used: rs79714374, rs12421289, rs12278319, rs7941782, rs4758267, rs12420464 and rs56392532. Haplotype C-CA-C-C-G-C harboring the missense variant, had a frequency of 3.5\% in 1818 independent, house-internal control WES from Germany. Genotypes of rs79714374 and rs56392532 in [brackets] had a low coverage, but due to very high linkage disequilibrium, their genotypes in individuals of P2, P3, P6, P10, P12, P17 could be tagged by rs12420464 and rs12421289, respectively. Genotypes in \{other brackets\} could be inferred in single individuals of P10, P17 due to available genotypes in other core family members and the ones in lowercase in [brackets] in P4 from haplotypes in 1818 control WES

P, pedigree; n.a, not applicable

$\S$ c.861dup/ p.(GIn288AlafsTer14) is on the underlined haplotype in P3 (frequency of 0.158 in controls)

gene panel for short stature and testing for Russel-Silver syndrome (OMIM \#180860). The individual compound heterozygous for EIF3F variants presented with intrauterine growth retardation. Most other genetic testing that was performed in affected individuals (Angelman syndrome, Fragile X-syndrome) overlapped those reported previously [9].

Heterozygous carriers were mainly asymptomatic. One father was reported to have epilepsy, and one mother migraines. Those overlapping symptoms are likely unrelated and of different etiology.

To test whether the missense variant arose once or recurrently, we performed haplotype analyses. This revealed that the EIF3F variant was on an identical haplotype (minimal $7.8 \mathrm{~kb}$ ) in 15 affected individuals of all tested families, suggesting a founder variant (Table 1).

\section{Discussion}

Our study confirms a relevant role of EIF3F in syndromic NDD. We observed the same pathogenic homozygous missense variant c.694T>G/ p.(Phe232Val) in all but one affected individual. This variant represents the $7^{\text {th }}$ most common EIF3F missense variant in gnomAD (0.07\%) with highest frequencies in Ashkenazi Jewish (0.21\%) and non-Finnish European individuals (0.12\%) [6]. In line with its pathogenicity, no individual in gnomAD was reported to be homozygous for this variant, in contrast to five of the six more frequent variants. The haplotype analyses performed in this study add the finding that the variant most probably arose once on a single haplotype, indicating a founder variant.

EIF3F was previously reported to be one of few genes significantly enriched for bi-allelic genotypes in large cohorts of individuals with NDD, due to the shared variant c.694T>G/ p.(Phe232Val) in all affected individuals [9]. The frequency of heterozygous carriers in gnomAD, especially in Non-Finnish European and Askenazi Jewish individuals, is higher than for most other autosomal recessive NDDs. For many of the other autosomal recessive NDDs, only few or a handful of families have been reported $[1,11]$. In those diseases, predominantly truncating variants are causative. Therefore, an identical, rather frequent missense variant in EIF3F in almost all affected individuals is an uncommon finding in NDDs, particularly in a cohort with heterogeneous, ethnical and regional backgrounds. Particularly common pathogenic variants have been observed in certain other genetic diseases: e.g. p.Phe508del variant in CFTR in cystic fibrosis in Europeans, population-specific variants in $H F E$ in 
Table 2 Clinical features of individuals with bi-allelic EIF3F variants

\begin{tabular}{|c|c|c|}
\hline Feature & $\begin{array}{l}\text { Current study (total no. of indiv. with data; percent of } \\
\text { aff. indiv.) }\end{array}$ & $\begin{array}{l}\text { Published study (total no. of indiv. with data; } \\
\text { percent of aff. indiv.) [9] }\end{array}$ \\
\hline Homozygous for c.694T>G/ p.(Phe232Val) & $16(17 ; 94 \%)$ & $9(9 ; 100 \%)$ \\
\hline Parental consanguinity & $1(17 ; 6 \%)$ & $0(7 ; 0 \%)$ \\
\hline \multicolumn{3}{|l|}{ Family history } \\
\hline Affected sibling(s) (bi-allelic EIF3F variants) & $4(17 ; 24 \%)$ & $2(9 ; 22 \%)$ \\
\hline Parents with neurological symptoms & 2 parents (34; 6\%; epilepsy or migraines) & 1 parent $(14 ; 7 \%$; mild ID) \\
\hline \multicolumn{3}{|l|}{ Gender } \\
\hline Female & $15(68 \%)$ & $5(56 \%)$ \\
\hline Male & $7(32 \%)$ & $4(44 \%)$ \\
\hline Average age at last examination in years (median) & $12.1 \pm 9.6(8.5)$ & $16.3 \pm 13.4(13.0)$ \\
\hline \multicolumn{3}{|l|}{ Pregnancy/delivery } \\
\hline Eventful pregnancy & 1 (21; 5\%; oligo-hydramnios) & 1 (9; 11\%; abnormal prenatal scan) \\
\hline Premature delivery & $2(20 ; 10 \%)$ & $0(9 ; 0 \%)$ \\
\hline Perinatal asphyxia & $1(19 ; 5 \% ;$ suspected) & $0(9 ; 0 \%)$ \\
\hline \multicolumn{3}{|l|}{ Development } \\
\hline Global developmental delay & $21(21 ; 100 \%)$ & $9(9,100 \%)$ \\
\hline Speech delay & $21(21 ; 100 \%)$ & n.a \\
\hline No speech & $5(21 ; 24 \%)$ & n.a \\
\hline Regression & $3(21 ; 14 \%)$ & n.a \\
\hline Behavioral problems & $12(21 ; 57 \%)$ & $6(9 ; 33 \%)$ \\
\hline Hearing loss & $12(21 ; 57 \%)$ & $3(9 ; 33 \%)$ \\
\hline Muscular hypo-/hypertonia & $10(21 ; 48 \%)$ & (\%) \\
\hline \multicolumn{3}{|l|}{ Ophthalmological findings } \\
\hline Hyper-/myopia & $8(21 ; 38 \%)$ & \\
\hline Strabismus & $3(21 ; 14 \%)$ & $1(9 ; 11 \%)$ \\
\hline Nystagmus & $1(21 ; 5 \%)$ & \\
\hline Coloboma & $1(21 ; 5 \%)$ & \\
\hline \multicolumn{3}{|l|}{ Brain imaging } \\
\hline Nonspecific findings & $5(13 ; 38 \%)$ & $3(7 ; 43 \%)$ \\
\hline Sleeping problems & $5(21 ; 24 \%)$ & n.a \\
\hline Epilepsy_confirmed & $3(20 ; 15 \%)$ & $6(7 ; 86 \%)$ \\
\hline \multicolumn{3}{|l|}{ Other neurological issues } \\
\hline Encephalopathy & $1(21 ; 5 \%)$ & n.a \\
\hline Meningioma & $2(21 ; 10 \%)$ & \\
\hline Psychosis & $1(21 ; 5 \%)$ & \\
\hline \multicolumn{3}{|l|}{ Body measurements } \\
\hline Microcephaly at birth & $4(10 ; 40 \%)$ & $0(1 ; 0 \%)$ \\
\hline Short stature at birth & $3(15 ; 20 \%)$ & n.a \\
\hline Microcephaly later & $6(19 ; 32 \%)$ & $1(8 ; 13 \%)$ \\
\hline Short stature later & $8(20 ; 40 \%)$ & $1(4 ; 25 \%)$ \\
\hline \multicolumn{3}{|l|}{ Malformations } \\
\hline Cleft lip/ palate (incl. minor form) & $2(20 ; 10 \%)$ & $1(9 ; 11 \%)$ \\
\hline Gastrointestinal symptoms & $5(21 ; 24 \%)$ & n.a \\
\hline \multicolumn{3}{|l|}{ Dysmorphisms } \\
\hline Fine facial features & $2(19 ; 11 \%)$ & n.a \\
\hline Findings of nose & $5(20 ; 25 \%)$ & \\
\hline Posteriorly rotated ears & $7(20 ; 35 \%)$ & \\
\hline Deep set or encased nails of fingers and/ or toes & $6(20 ; 30 \%)$ & n.a \\
\hline Abnormality 5th finger/ toe (shortness, clinodactyly) & $3(20 ; 15 \%)$ & \\
\hline Short hands/ feet or slender fingers/ toes & $5(20 ; 25 \%)$ & \\
\hline Flat feet & $3(20 ; 15 \%)$ & \\
\hline
\end{tabular}


Table 2 (continued)

Each row indicates the number of individuals/ families with the specified feature (number in parantheses indicate number of individuals with available information on this feature and percentage). Due to an additional confounding diagnosis of MECP2-related disorder in affected individual of P2 and the issue of overlapping phenotypes, we considered this individual only for the first four categories, but no further aspects

aff. indiv.: affected individuals; incl.: including; n.a. not applicable; No./ no.: number

hemochromatosis, and population-specific truncating variants in GJB2 in deafness. In this study, the EIF3F missense variant was identified in affected individuals of a wide spectrum of European/ West Asian origins including French, English, Irish, Scottish, German, Bulgarian, Ukranian, Russian, Ashkenazi Jewish, and Iraqi. Haplotype analyses support a single mutational event on a founder haplotype, while the nascence of the missense variant cannot be determined to a more localized region.

As only the identical missense variant in EIF3F has been functionally characterized and shown to result in reduced protein amount/ stability, decreased proliferation rate and reduced translational rate, it remains speculative whether other missense variants might have comparable effects. Other rare missense variants might be functionally irrelevant or less harmful, as they might reach a certain harmful threshold causing NDD as in case of c.694T $>$ G/ p.(Phe232Val) [9]. In contrast, the finding of the rather severe phenotype in the individual with compound heterozygous variants in EIF3F suggests some genotype-phenotype correlation and a possibly residual EIF3F function in individuals homozygous for c.694T $>$ G/ p.(Phe232Val). Of note, the overall number of truncating alleles in individuals in gnomAD v2.1.1 is extremely low (probability of being loss-of-function intolerant $=0.97$, observed over expected variants $=0.07$ ). Regarding lack of individuals with two truncating variants and of further affected individuals who are compound heterozygous for truncating variants, one might speculate that truncating variants on both alleles might not be compatible with life.

In this study, all affected individuals had global developmental delay of variable degree. Motor developmental delay was variable: one patient did not learn to walk independently, while most individuals learned walking late, and some individuals achieved motor milestones at a normal age. Similarly, the degree of ID varied widely. This study adds the finding of significant speech delay to the phenotype: the majority of individuals spoke more than few words, while a quarter of affected individuals had no speech development. In comparison to the initial report [9], hearing loss and behavioral difficulties were more common findings, and epilepsy less frequent in this study. Other frequent, so far unreported symptoms observed in this study are muscular hypotonia and/ or hypertonia, ophthalmologic findings and sleeping problems. Results of a murine study might indicate some
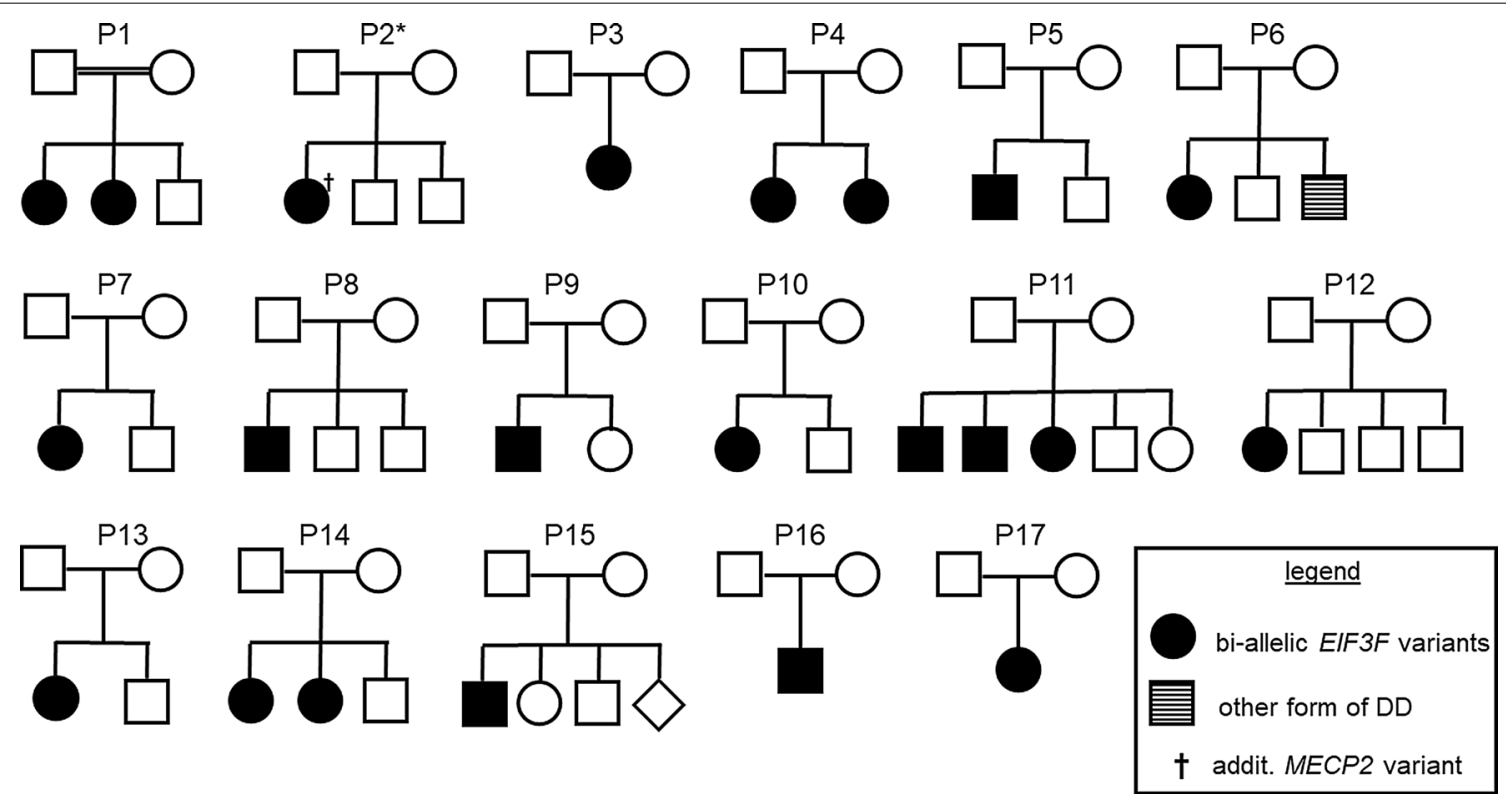

Fig. 1 Pedigrees of 17 families with EIF3F-related NDD. All parents, but the ones of P16 were identified as heterozygous carriers of EIF3F variants. P3 is the family with the compound heterozygous individual. P, pedigree. ${ }^{\dagger}$ Individual with an additional, de novo MECP2 variant. DD, developmental delay; P, pedigree 

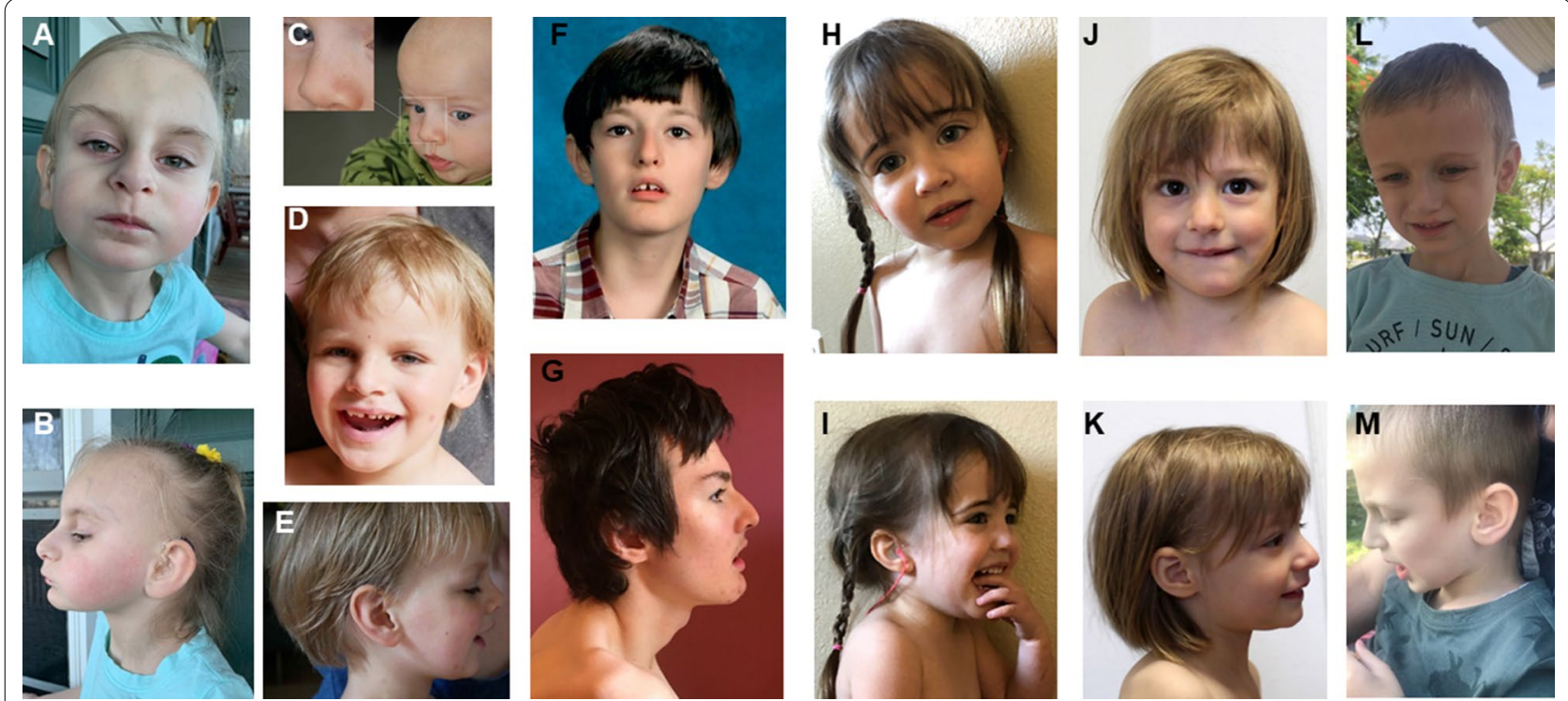

Fig. 2 Frontal and lateral facial profiles of six affected individuals carrying bi-allelic EIF3F variants. a, b represent P3 at $5 y, \mathbf{c} P 5$ at $4 \mathrm{~m}$ and $\mathbf{d}$, e P5 at $4 y 3 \mathrm{~m}, \mathbf{f}, \mathbf{g}$ show P9 at $13 y$ and at $17 \mathrm{y}$, respectively, $\mathbf{h}, \mathbf{i}$ P12 at 2 y $8 \mathrm{~m}, \mathbf{j}, \mathbf{k}$ P13 at $3 y$ 2m and $\mathbf{I}, \mathbf{m}$ P15 at $6 y$ m. All affected individuals have fairly even palpebral fissures, a pointed nasal tip which is rather prominent for age at lateral view. Note nasal fistula and groove at left lip in P5 before surgery (c), and after correction (d). $y=$ years; $m=$ months

concordance with the human phenotype and support loss-of-function as the underlying cause: partial depletion of murine eIF3f amplified muscle atrophy compared to wild-type mice and reduced the MTOR pathway activation [3]. In regard to this study's ophthalmologic findings, some of these (hyper-/ myopia) might not necessarily be related to EIF3F deficiency, as they are common in the general population.

The observation of reduced pain sensitivity in this study supports an association with this previously described, however rare symptom [9], as did the finding of muscular atrophy/ muscular hypoplasia in another individual. In concordance with the previous study, brain imaging did not reveal specific findings and were therefore not considered diagnostically indicative in EIF3F related NDD. Thus, genome-wide sequencing approaches (genome or exome sequencing) represent an essential component of the diagnostic work-up.

Developmental regression or neurodegeneration at various ages ( 2.5 to $\sim 30$ years) was observed in three of the 20 affected individuals which might be relevant for prognosis. However, two of the three individuals had additional diagnoses that are not necessarily related to this syndromic disorder: encephalopathy in an individual with vitamin B12 deficiency and psychosis in an individual with meningioma. In another individual, an increased seizure frequency also led to the diagnosis of meningioma. The cohort size and the relatively young ages of the majority of individuals did not allow conclusions as to whether those symptoms are part of the disease spectrum or might have an independent cause. In large collections of malignancies (COSMIC; accessed on $3^{\text {rd }}$ of December 2020 at cancer.sanger.ac.uk), somatic EIF3F variants have been detected in $0.9 \%$ of 38,579 samples $(\mathrm{n}=353)$ and did not include 130 meningioma samples, providing no further evidence for a role of EIF3F in tumorigenesis of meningioma [16].

Short stature, also occurring until adulthood, was commonly observed in this study group. Microcephaly was less frequent than short stature and of variable degree within this cohort, while longitudinal data indicated that head growth had a more constant course along the centiles than height.

Rare features that might be part of the EIF3F related NDD include functional problems of the gastrointestinal tract, undescended testes, cleft lip and palate, heart defect and nasal fistula. Of those, the latter two had not been previously described. In agreement with the previous study, we did not recognize an obvious distinctive facial appearance. While the previous study had indicated tapered fingers and dysplastic toe nails [9], we observed nasal findings (tubular nose, pointed nasal tip, anteverted nares), posteriorly rotated ears as well as short and/ or encased finger and toe nails as more frequent, recurrent features.

In summary, this study confirms the previously reported $E I F 3 F$ missense variant as a relatively frequent 

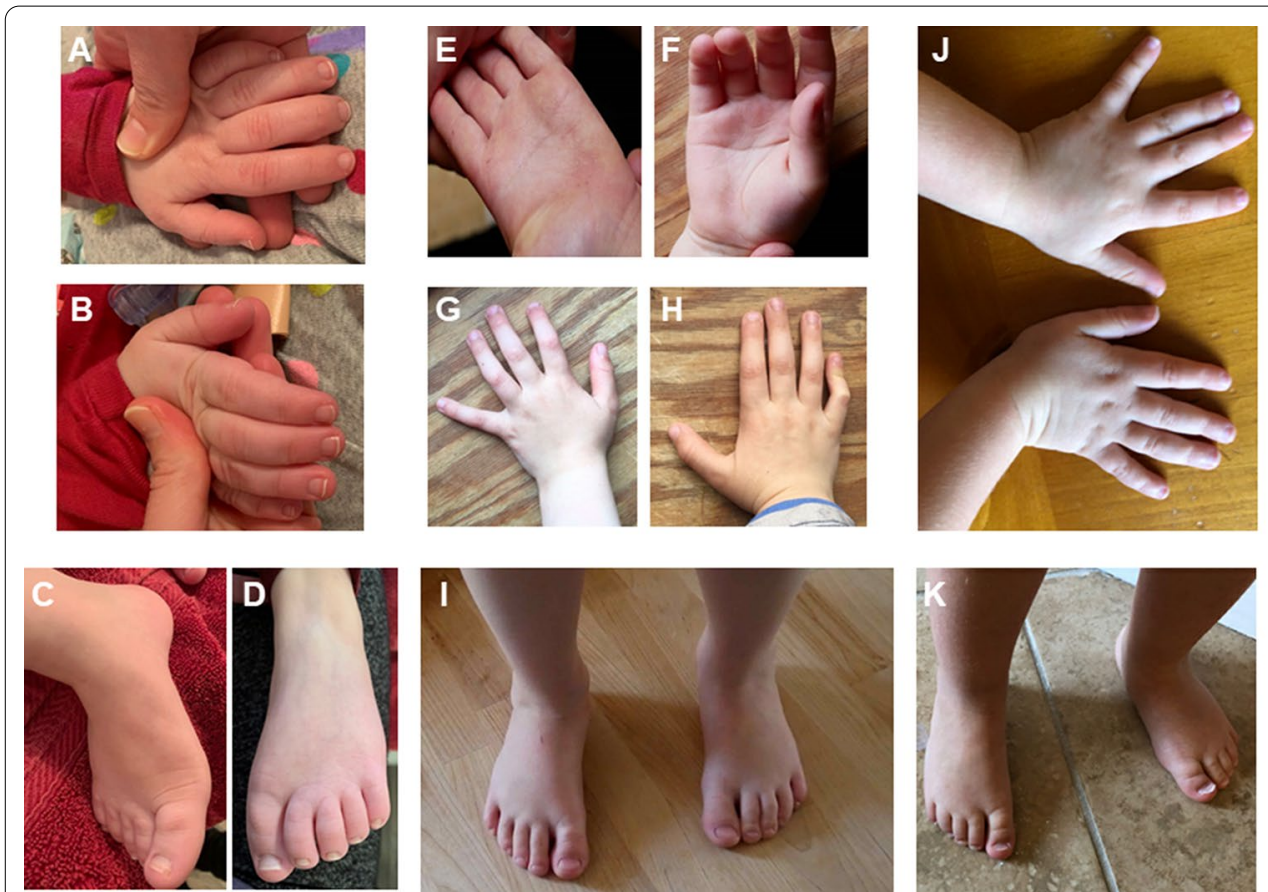

Fig. 3 Hands and feet of four affected individuals carrying bi-allelic EIF3F variants. a-d represent P3 at 5y, e-i P5 at 4y $3 \mathrm{~m}, \mathbf{j}, \mathbf{k}$ P12 at 2y $8 \mathrm{~m}$, and $\mathbf{I}, \mathbf{m}$ P13 at 3y $2 \mathrm{~m}$. Some affected individuals have puffy backs of hands and feet; most individuals have encased nails (= nails embedded by skin), predominantly of the finger nails and short toe nails. $y=$ years; $m=$ months

cause of autosomal-recessive NDD. Characteristic features include global developmental delay, delayed speech development, behavioral difficulties, altered muscular tone, hearing loss, ophthalmological symptoms, short stature, and minor anomalies of the ears, nose, hands and feet.

\section{Supplementary Information}

The online version contains supplementary material available at https://doi. org/10.1186/s13023-021-01744-1.

Additional file 1: Table S1. Detailed clinical information.

Additional file 2: Fig S1. Examples of sequences of disease-causing variant c.694T $>$ G/ p.(Phe232Val) at individual basis.

\section{Acknowledgements}

We are grateful to all affected individuals and families whose participation in the study enabled the data collection and the analyses. We also thank Hilary C. Martin as the corresponding author of the previous study, and Erin Torti (GeneDx) for referring collaborators to our common study.

\section{Authors' contributions}

UH and $C Z$ designed the study. UH, CKr, MSR, SU, MAA, SAA, KLAR, EB, HLi, ALB, LF, FTMT, CB, SB, KB, IW, MDC, JAMA, HLE, SFN, CCRD, PZ, RAJ, CKI, JMG, JK, SS, EM, JP, ARR, MJGS, LBH, TBP, SVM, HZE, AdR, SASV, EW, AnR and CZ contributed patient or genetic data or were involved in interpretation of data. UH wrote the manuscript that was read, revised and approved by all other coauthors. All authors read and approved the final manuscript.

\section{Funding}

Open Access funding enabled and organized by Projekt DEAL. Part of this study was funded by project E31 of the Interdisciplinary Center of Clinical Research (IZKF) of the Medical Faculty of Erlangen-Nürnberg to CZ. Whole genome sequencing for family 9 was supported by the NIH National Center for Advancing Translational Science (NCATS) UCLA Clinical and Translational Science Institute (CTSI) Grant Number UL1TR001881 and the UCLA California Center for Rare Diseases.

\section{Availability of data and materials}

All data generated or analyzed during this study are included in this published article and its supplementary information files.

\section{Ethics approval and consent to participate}

The study was approved by the ethical committee of the Friedrich-AlexanderUniversität Erlangen-Nürnberg (253_15 B, 71_17 B), and by local ethics boards of the contributing institutions.

\section{Consent for publication}

All parents or the legal guardians gave written informed consent before enrollment, including consent to publish clinical pictures of the six patients shown in Figs. 2 and 3.

\section{Competing interests}

The authors MJGS, LBH, TBP, SVM, HZE and AdR are employees of GeneDX, Inc. All other authors declare to have no competing interests.

\section{Author details}

${ }^{1}$ Institute of Human Genetics, Universitätsklinikum Erlangen, FriedrichAlexander-Universität Erlangen-Nürnberg (FAU), Schwabachanlage 10, 91054 Erlangen, Germany. ${ }^{2}$ Medical Genetics, Department of Pediatrics, University of Massachusetts Medical School - Baystate, Springfield, MA, USA. ${ }^{3}$ Department of Genetics, Southern California Permanente Medical Group, 
Kaiser Permanente, Riverside, CA, USA. ${ }^{4}$ Department of Human Genetics, Emory University School of Medicine, Atlanta, GA 30322, USA. ${ }^{5}$ UMR-Inserm 1231 GAD Team, Génétique des Anomalies du développement, Université de Bourgogne Franche-Comté, 21000 Dijon, France. ${ }^{6}$ Laboratoire de Génétique Chromosomique et Moléculaire, UF Innovation en diagnostic génomique des maladies rares, Plateau de Biologie Hospitalo-Universitaire, Centre Hospitalier Universitaire de Dijon, Dijon, France. ${ }^{7}$ Centre de Génétique, Centre de Référence «Anomalies du Développement et Syndromes Malformatifs» et FHU TRANSLAD, Hôpital D'Enfants, Centre Hospitalier Universitaire de Dijon, Dijon, France. ${ }^{8}$ Division of Medical Genetics, Department of Pediatrics, Rutgers Robert Wood Johnson Medical School, New Brunswick, NJ 08901, USA. ${ }^{9}$ Sanford Health, Sioux Falls, SD, USA. ${ }^{10}$ Division of Genetics, Department of Pediatrics, David Geffen School of Medicine, University of California at Los Angeles, Los Angeles, CA 90095, USA. ${ }^{11}$ Department of Human Genetics, David Geffen School of Medicine, University of California at Los Angeles, Los Angeles, CA 90095, USA. ${ }^{12}$ Pathology and Laboratory Medicine, David Geffen School of Medicine, University of California at Los Angeles, Los Angeles, CA 90095, USA. ${ }^{13}$ UCLA California Center for Rare Diseases, David Geffen School of Medicine, University of California at Los Angeles, Los Angeles, CA 90095, USA. ${ }^{14}$ Institute of Human Genetics, University of Leipzig Medical Center, Leipzig, Germany. ${ }^{15}$ Epilepsy Center Kleinwachau, Radeberg, Germany. ${ }^{16}$ Genetic Health Queensland, Royal Brisbane and Woman's Hospital, Brisbane, Australia. ${ }^{17}$ School of Medicine, The University of Queensland, St Lucia, Brisbane, Australia. ${ }^{18}$ Synlab Human Genetics Freiburg, Freiburg, Germany. ${ }^{19}$ Clinical Genetics, Hassenfeld Children's Hospital at NYU Langone, NYU Langone, Orthopedic Hospital, New York, NY, USA. ${ }^{20}$ Division of Clinical Genetic Services, Department of Pediatrics, NYU Grossman School of Medicine, New York, NY, USA.

${ }^{21}$ Sackler School of Medicine at Tel Aviv University, Tel Aviv, Israel. ${ }^{22}$ Institute of Rare Diseases, Edmond \& Lily Safra Children Hospital, Tel Hashomer, Israel. ${ }^{23}$ GeneDx, Gaithersburg, MD 20877, USA. ${ }^{24}$ Division of Medical Genetics and Metabolism, Children's Hospital of The King's Daughters, Norfolk, VA, USA. ${ }^{25}$ Division of Genetics, UBMD Pediatrics, Buffalo, NY, USA. ${ }^{26}$ Present Address: Department of Human Genetics, Inselspital, Bern University Hospital, University of Bern, Bern, Switzerland.

Received: 10 December 2020 Accepted: 15 February 2021 Published online: 18 March 2021

\section{References}

1. Anazi S, Maddirevula S, Salpietro V, Asi YT, Alsahli S, Alhashem A, et al. Expanding the genetic heterogeneity of intellectual disability. Hum Genet. 2017;136(11-12):1419-29. https://doi.org/10.1007/s0043 9-017-1843-2.

2. Barrett JC, Fry B, Maller J, Daly MJ. Haploview: analysis and visualization of LD and haplotype maps. Bioinformatics. 2005;21(2):263-5.

3. Docquier A, Pavlin L, Raibon A, Bertrand-Gaday C, Sar C, Leibovitch S, et al. elF3f depletion impedes mouse embryonic development, reduces adult skeletal muscle mass and amplifies muscle loss during disuse. J Physiol. 2019;597(12):3107-31. https://doi.org/10.1113/JP277841.

4. Hauer NN, Popp B, Schoeller E, Schuhmann S, Heath KE, Hisado-Oliva A, et al. Clinical relevance of systematic phenotyping and exome sequencing in patients with short stature. Genet Med. 2018;20(6):630-8. https://doi. org/10.1038/gim.2017.159.

5. Huffmeier U, Lascorz J, Bohm B, Lohmann J, Wendler J, Mossner R, et al. Genetic variants of the IL-23R pathway: association with psoriatic arthritis and psoriasis vulgaris, but no specific risk factor for arthritis. I Invest Dermatol. 2009;129(2):355-8. https://doi.org/10.1038/jid.2008.233.

6. Karczewski KJ, Francioli LC, Tiao G, Cummings BB, Alfoldi J, Wang Q, et al. The mutational constraint spectrum quantified from variation in 141,456 humans. Nature. 2020;581(7809):434-43. https://doi.org/10.1038/s4158 6-020-2308-7.

7. Kromeyer-Hauschild K, Wabitsch M, Kunze D, Geller F, Geiß HC, Hesse V, et al. Perzentile für den Body-mass-Index für das Kindes- und Jugendalter unter Heranziehung verschiedener deutscher Stichproben. Monatsschrift Kinderheilkunde. 2001;149(8):807-18. https://doi.org/10.1007/s0011 20170107.

8. Lee AS, Kranzusch PJ, Cate JH. elF3 targets cell-proliferation messenger RNAs for translational activation or repression. Nature. 2015;522(7554):111-4. https://doi.org/10.1038/nature14267.

9. Martin HC, Jones WD, McIntyre R, Sanchez-Andrade G, Sanderson M, Stephenson JD, et al. Quantifying the contribution of recessive coding variation to developmental disorders. Science. 2018;362(6419):1161-4. https://doi.org/10.1126/science.aar6731.

10. Masutani M, Sonenberg N, Yokoyama S, Imataka H. Reconstitution reveals the functional core of mammalian elF3. EMBO J. 2007;26(14):3373-83. https://doi.org/10.1038/sj.emboj.7601765.

11. Reuter MS, Tawamie H, Buchert R, Hosny Gebril O, Froukh T, Thiel C, et al. Diagnostic yield and novel candidate genes by exome sequencing in 152 consanguineous families with neurodevelopmental disorders. JAMA Psychiatry. 2017;74(3):293-9. https://doi.org/10.1001/jamapsychi atry.2016.3798.

12. Rumping L, Buttner B, Maier O, Rehmann $H$, Lequin $M$, Schlump JU, et al. Identification of a loss-of-function mutation in the context of glutaminase deficiency and neonatal epileptic encephalopathy. JAMA Neurol. 2019;76(3):342-50. https://doi.org/10.1001/jamaneurol.2018.2941.

13. Shieh C, Jones N, Vanle B, Au M, Huang AY, Silva APG, et al. GATAD2Bassociated neurodevelopmental disorder (GAND): clinical and molecular insights into a NuRD-related disorder. Genet Med. 2020;22(5):878-88. https://doi.org/10.1038/s41436-019-0747-z.

14. Sobreira N, Schiettecatte F, Valle D, Hamosh A. GeneMatcher: a matching tool for connecting investigators with an interest in the same gene. Hum Mutat. 2015;36(10):928-30. https://doi.org/10.1002/humu.22844.

15. Stephens M, Smith NJ, Donnelly P. A new statistical method for haplotype reconstruction from population data. Am J Hum Genet. 2001;68:978-89.

16. Tate JG, Bamford S, Jubb HC, Sondka Z, Beare DM, Bindal N, et al. COSMIC: the catalogue of somatic mutations in cancer. Nucleic Acids Res. 2019;47(D1):D941-7. https://doi.org/10.1093/nar/gky1015.

17. Voigt M, Fusch C, Olbertz D, Hartmann K, Rochow N, Renken C, Schneider KTM. Analyse des Neugeborenenkollektivs der Bundesrepublik Deutschland. Geburtshilfe Frauenheilkd. 2006;66:956-70. https://doi. org/10.1055/s-2006-924458.

\section{Publisher's Note}

Springer Nature remains neutral with regard to jurisdictional claims in published maps and institutional affiliations.

Ready to submit your research? Choose BMC and benefit from:

- fast, convenient online submission

- thorough peer review by experienced researchers in your field

- rapid publication on acceptance

- support for research data, including large and complex data types

- gold Open Access which fosters wider collaboration and increased citations

- maximum visibility for your research: over 100M website views per year

At BMC, research is always in progress.

Learn more biomedcentral.com/submissions 